\title{
Diagnóstico sobre a queda de árvores urbanas em Belo Horizonte-MG
}

\author{
Marina Moura de Souza $\oplus^{1}$ Agnus Rocha Bittencour $\circledast^{2}$ Angeline Martini $\circledast^{3 *}$ \\ 1 Companhia Energética de Minas Gerais - Cemig, Gerência de Coordenação da Manutenção da Distribuição, Av. Barbacena, 1200 , Santo \\ Agostinho, CEP 30190-131, Belo Horizonte, MG, Brasil \\ 2 Secretaria Municipal de Meio Ambiente de Belo Horizonte, Av. Afonso Pena, 342, $8^{\circ}$ andar, Centro, CEP 30.130-001, Belo Horizonte, MG, \\ Brasil \\ 3 Universidade Federal de Viçosa, Av. Peter Henry Rolfs, s/n - Campus Universitário, CEP 36570-900, Viçosa - MG, Brasil
}

Original Article
*Corresponding author:
martini.angeline@gmail.com

Palavras-chave:

Risco de queda

Potencial de falha

Análise de risco

Keywords:

Fall risk

Potential failure

Risk analysis

Received in

2019/03/31

Accepted on

2020/03/02

Published in

2020/04/03

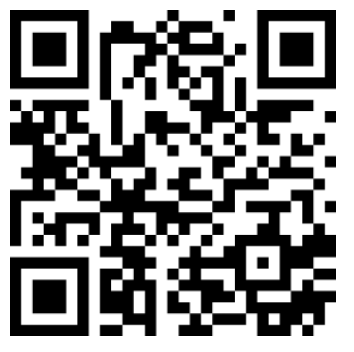

DOI:http://dx.doi.org/10.340 62/afs.v7i1.8134

\section{(cc) BY}

RESUMO: As árvores urbanas proporcionam inúmeros benefícios para a população, contribuindo significativamente para a melhoria da qualidade de vida. Contudo, tem sido frequente os transtornos ocasionados por queda de árvores nas grandes cidades. Desta forma, o objetivo da presente pesquisa foi realizar um diagnóstico sobre a queda de árvores urbanas em Belo Horizonte-MG. Para isso, os dados foram coletados por meio de amostragem aleatória após a ocorrência das quedas, entre os anos de 2015 e 2018. Sempre após o registro da queda, no local de ocorrência foram coletas as seguintes informações: identificação botânica, porte, condição de plantio, local de ruptura; qualidade da copa, troco e colo; presença de pragas ou sinais de doença. A análise, realizada em 69 exemplares arbóreos indicou a queda de 24 espécies pertencentes a 10 famílias botânicas. Sete espécies foram responsáveis por aproximadamente $60 \%$ das quedas registradas, destas, destacaramse as espécies Pachira aquatica e Libidibia ferrea var. leiostachya responsáveis por $10,1 \%$ das ocorrências cada uma e Poincianella pluviosa (8,7\%). Apenas 20,3\% das árvores apresentaram problemas fitossanitários, desencadeados principalmente pelo ataque do besouro metálico e por cupins nas raízes. A maioria foram plantadas em calçadas e apresentavam grande porte $(76,8 \%)$, com boas condições de copa (88\%), tronco $(88 \%)$ e colo (95\%), não evidenciando problemas, sendo a ruptura ocorrida principalmente nas raízes $(82,6 \%)$. Conclui-se, a condição de plantio onde houve falta de espaço ou dificuldade de enraizamento no solo urbano, teve relação direta com a queda, evidenciando a dificuldade de ancoragem em árvores de grande porte.

\section{Diagnosis of the fall of urban trees in Belo Horizonte, Brazil}

\begin{abstract}
Urban trees provide countless benefits for population, contributing significantly to the increase of quality of life. Have been frequent the disorders caused by tree falls in large cities. In this way, the present study made a diagnosis about the fall of urban trees in Belo Horizonte, Brazil. For this, the data were collected by means of random sampling after an occurrence of falls, between the years of 2015 and 2018. A researcher went to the place, always after registering the fall, to carry out a collection of information: size, condition of planting, place of rupture; quality of the crown, trunk and base of the trunk; presence of pests or signs of disease. An analysis of 69 tree indicated the fall of 24 species belonging to 10 botanical families. Seven species accounted for approximately $60 \%$ of recorded falls, of these, stood out Pachira aquatica and Libidibia ferrea var. leiostachya responsible for $10.1 \%$ of occurrences each and Poincianella pluviosa $(8.7 \%)$. Only $20.3 \%$ of the trees presented phytosanitary problems, triggered by the attack of Euchroma gigantea and the termites in the roots. Most were planted on sidewalks and had a large size $(76.8 \%)$, with good conditions of crown (88\%), trunk (88\%) and base of the trunk (95\%), not showing problems and the rupture occurred mainly in the roots. The condition of planting with lack of space or difficulty of rooting in the urban soil, had its direct relation with the fall, evidencing a difficulty of anchorage in large trees
\end{abstract}




\section{Introdução}

A floresta urbana é um componente que reestrutura a paisagem, permitindo interação das pessoas com elementos naturais. Inclui diferentes elementos, como manchas florestais, telhados verdes, jardins, gramados, paredes verdes, árvores de rua, parques e praças que fornecem os serviços ecossistêmicos necessários para o bem-estar humano e a conservação da biodiversidade (Pena et al. 2016). É inquestionável que árvores, principal componente da floresta urbana, exercem um papel vital para o bem-estar das comunidades. Sua capacidade única de controlar muito dos efeitos adversos do meio urbano contribui para uma significativa melhoria da qualidade de vida (Volpe-Filik et al. 2007).

Mesmo desempenhando um papel fundamental na vida da população urbana a arborização não recebe prioridade, resultado da inexistência de políticas no setor e da falta de projetos adequados. Muitas vezes os projetos de arborização são criados de maneira improvisada, gerando vários conflitos com o ambiente urbano, como: estragos em calçadas, redes de esgoto ou de água, danos em construções, interferência em bueiros, dificuldade de visualização de placas de orientação, restrição da passagem de pedestres ou veículos, dentre outros (Pereira et al. 2011).

Aliado a esta falta de planejamento adequado, tem-se ainda, o fato de os centros urbanos, não oferecem um local ideal para o desenvolvimento das árvores, devido à extrema artificialidade e demais funcionamento dos elementos antrópicos predominantes. As diferentes condições impostas às espécies arbóreas prejudicam seu crescimento e desenvolvimento, que é diferente nos ambientes naturais.

Apesar da importância da floresta para a qualidade de vida, o planeamento e a gestão inadequados podem promover riscos para a população e resultar em perdas materiais ou mesmo fatalidades (Bressane et al. 2018). O aumento da ocorrencias de quedas de árvores nos centros urbanos tem se intensificado nos últimos anos, causada por condicionantes, como: chuvas fortes e longas, podas irregulares, rajadas de vento e raiz instável (Sampaio et al. 2010). Tem-se ainda outros fatores que podem interferir diretamente nas chances de quedas de árvores, como: o corte de raízes, uso indevido de espécies e a compactação do solo (Moser et al. 2010).

Desta forma, a queda de árvores e/ou de galhos tornou-se um problema grave em cidades de todo o mundo (Pereira et al. 2011). Portanto, desenvolver pesquisas para aprimorar as medidas mitigadoras tornam-se essenciais, principalmente aquelas que dão suporte às práticas de manejo das árvores. Tais investimento podem diminuir os valores gastos com indenizações decorrentes de danos provocados por indivíduos arbóreos, aumentar a beleza cênica da cidade e evitar quebras e rachaduras nas vias públicas (Skärbäck 2007).

A carência de pesquisas sobre quedas de árvore resulta na falta de soluções eficazes para sanar este problema, que precisam ser elaboradas com fundamentos científicos concretos e não especulativo. No entanto, faltam ainda informações básicas e iniciais sobre esta questão. Neste sentido, objetivo da presente pesquisa foi realizar um diagnóstico sobre a queda de árvores urbanas em Belo Horizonte, em vista de apontar os fatores que mais contribuem para este problema.

\section{Material e Métodos}

A pesquisa foi realizada em Belo Horizonte, capital do Estado de Minas Gerais, localizada a 767 $\mathrm{m}$ de altitude, no sudeste do Brasil (latitude $19^{\circ} 48^{\prime} 57^{\prime}$ ' S e longitude $43^{\circ} 57^{\prime} 15^{\prime}$ ' O). A cidade possui uma população estimada em 2.501.576 habitantes, distribuídos em uma área de 331,401 $\mathrm{km}^{2}$, com densidade demográfica de 7.167 hab. $/ \mathrm{km}^{2}$ (IBGE, 2019). Segundo classificação climática de Köppen-Geiger, localiza-se em região climática do tipo Aw, denominada tropical com seca no inverno (Martins et al. 2018). A temperatura média anual é de $21,1^{\circ} \mathrm{C}$, com média de $29,0^{\circ} \mathrm{C}$ nos meses mais quentes e $12,9^{\circ} \mathrm{C}$ nos mais frios, e precipitação anual é de 1491,3 mm com maior concentração nos meses de verão (Assis 2010).

Belo Horizonte, está inserida na área de transição entre os domínios da Mata Atlântica e Cerrado. Segundo Pena et al. (2016) a cidade foi criada sob o conceito de "cidade jardim", sendo famosa nas primeiras décadas após sua fundação, devido a alta densidade de jardins, praças públicas e ruas arborizadas. Porém, na década de 60, após enfrentar um crescimento da população, sofreu intensas mudanças na paisagem, reduzindo a quantidade e a diversidade de árvores e áreas verdes. Atualmente sua infraestrutura é composta por áreas verdes dispersas, como praças e parques públicos, além das árvores nas ruas. Os índices do IBGE (2019) demonstram que $82,7 \%$ das casas estão em vias públicas arborizadas

O diagnoóstico sobre a queda de árvores foi realizado por meio de um estudo de caso exploratório, com expedições a campo entre os anos de 2015 e 2018. Neste período, após a ocorrência de quedas de árvore informada na mídia, uma equipe de pesquisadores se deslocava até o local informado e obtiveram a coleta de dados in loco, com informações sobre as árvore somente após a sua queda (Figura 1). 


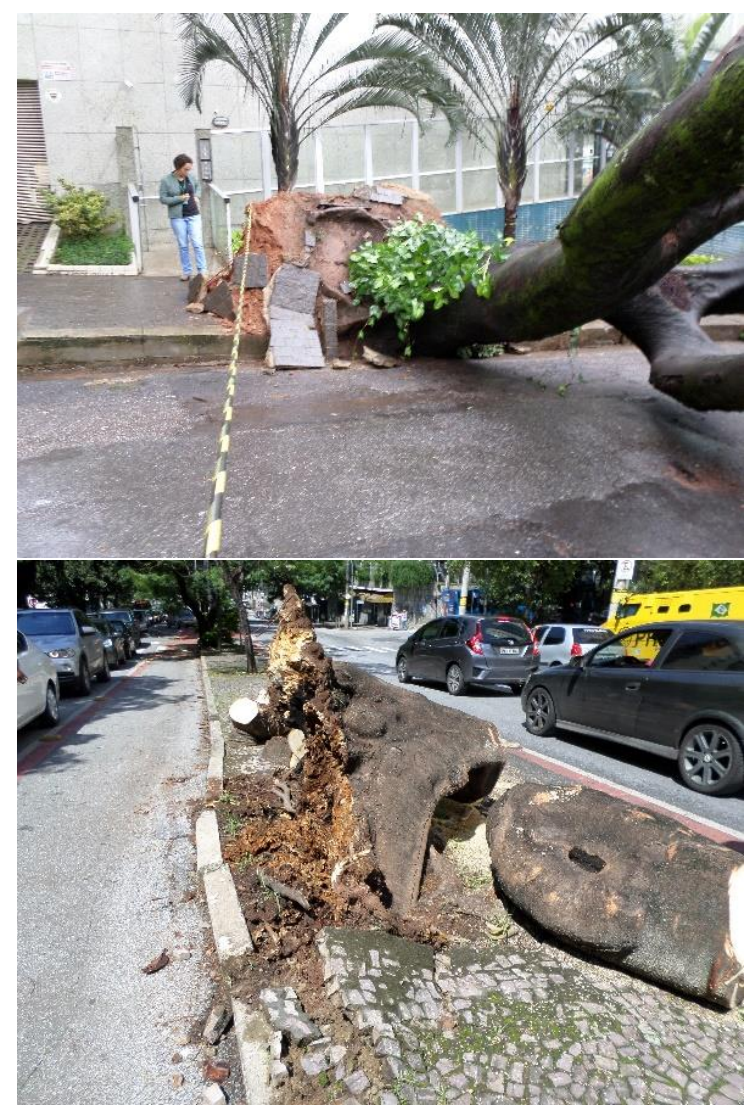

Figura 1. Coleta de dados em campo após a ocorrência da queda de árvore.

A amostragem foi realizada de maneira aleatória e as variáveis coletadas em campo foram:

a) data e hora da ocorrência;

b) endereço - rua, bairro, região;

c) identificação botânica da espécie;

d) CAP (circunferência a altura do peito) medido com fita métrica e posteriormente transformado em DAP (diâmetro a altura do peito);

e) porte - definido por meio de estimativa visual e classificado em pequeno (até $8 \mathrm{~m}$ ), médio ( 8 a $12 \mathrm{~m}$ ) e grande (acima de $12 \mathrm{~m}$ );

f) local de plantio - calçada, canteiro central, praça, lote;

g) local da ruptura das árvores (raiz, colo, tronco);

h) altura da ruptura das árvores, medido apenas para as situações ocorridas no tronco;

i) condições da qualidade do colo - boa (não apresenta qualquer defeito); média (há algum sinal pequeno de cavidade, necrose ou injúria); ruim (com sinais profundos de defeitos, necroses ou outra injúria);

j) condições da qualidade do tronco - boa (não apresenta qualquer defeito); média (há algum sinal pequeno de cavidade, necrose ou injúria); ruim (com sinais profundos de defeitos, necroses ou outra injúria);

k) condições da qualidade da copa - boa (não apresenta qualquer defeito); média (com pequenos ou poucos sinais de defeitos); ruim (com sinais profundos de defeitos);

1) direção da queda - identificação do sentido geográfico, com base nos pontos cardeais, norte, sul, leste, oeste;

m) dano provocado - descrição dos problemas gerados pela queda;

n) descrição da condição meteorológica referente a vento (fraco, forte, inexistente) e chuva (forte, constante e inexistente).

Os dados coletados em campo foram tabulados em planilha do software Microsoft Office Excel onde também foram processados. Os nomes científicos das espécies foram conferidos e atualizados no site do Jardim Botânico do Rio de Janeiro, onde também se obteve a informação da família botânica e origem da espécie - exótica, nativa do Brasil e nativa de Belo Horizonte (referentes às de ocorrência nas fitofisionomias locais, Mata Atlântica e Cerrado).

A essa planilha incorporou-se também os dados meteorológicos obtidos junto ao Instituto Nacional de Meteorologia (INMET), registrados na estação convencional oficial de Belo Horizonte, nas datas em que ocorreram as quedas das árvores amostradas. As variáveis meteorológicas utilizadas foram velocidade do vento média $(\mathrm{m} / \mathrm{s})$ e precipitação total acumulada $(\mathrm{mm})$, sendo esta última obtida do dia seguinte a data de queda, uma vez que a estação convencional obtém o registro acumulado das chuvas nas últimas $24 \mathrm{~h}$ às 12 UTC, equivalente às $9 \mathrm{~h}$ da manhã pelo horário de Brasília.

\section{Resultados e discussão}

As inferências foram realizadas com base no diagnóstico de 69 registros de quedas de árvores ocorridos em Belo Horizonte, ao longo dos quatro anos, com maior frequência no ano de 2018 (42,0\%), seguido pelo ano de 2016 (31,9\%), $2015(17,4 \%)$ e $2017(8,7 \%)$. A frequência de registros amostrados não reflete a proporção de árvores caídas por ano e sim a frequência de amostragem, pois a metodologia adotada foi aleatória e assim tais resultados, servem apenas para espacializar a coleta de dados.

Os registros indicaram a queda de 24 espécies pertencentes a 10 famílias botânicas (Tabela 1). A família que apresentou o maior número de queda dos indivíduos foi Fabaceae, correspondente a 46,3\% do total. Destaca-se também as famílias Bignoniaceae $(16,4 \%)$ e Malvaceae $(13,4 \%)$, a primeira devido ao grande número de ipês e a segunda representada principalmente pelas mungubas. 
Tabela 1. Informação sobre as espécies amostradas, nome científico, popular, família, origem (O) e número de indivíduos amostrados $(\mathrm{N})$.

\begin{tabular}{|c|c|c|c|c|}
\hline Nome científico & Nome popular & Família & $\mathbf{O}$ & $\mathbf{N}$ \\
\hline Pachira aquatica Aubl. & munguba & Malvaceae & $\mathrm{N}$ & 7 \\
\hline Libidibia ferrea var. leiostachya (Benth.) L.P.Queiroz & pau-ferro & Fabaceae & $\mathrm{N}$ & 7 \\
\hline Poincianella pluviosa (DC.) L.P.Queiroz & sibipiruna & Fabaceae & $\mathrm{N}$ & 6 \\
\hline Delonix regia (Bojer ex Hook.) Raf. & flamboyant & Fabaceae & $\mathrm{E}$ & 5 \\
\hline Bauhinia variegata $\mathrm{L}$. & pata-de-vaca & Fabaceae & $\mathrm{E}$ & 5 \\
\hline Handroanthus heptaphyllus (Vell.) Mattos & ipê-roxo & Bignoniaceae & $\mathrm{NBH}$ & 5 \\
\hline Lagerstroemia speciosa (L.) Pers. & escumilha-africana & Lythraceae & $\mathrm{E}$ & 5 \\
\hline Tipuana tipu (Benth.) Kuntze & tipuana & Fabaceae & $\mathrm{E}$ & 3 \\
\hline Holocalyx balansae Micheli & alecrim-de-campinas & Fabaceae & $\mathrm{NBH}$ & 3 \\
\hline Handroanthus serratifolius (Vahl) S.Grose & ipê-amarelo & Bignoniaceae & $\mathrm{NBH}$ & 2 \\
\hline Tabebuia rosea (Bertol.) Bertero ex A.DC. & ipê-rosado & Bignoniaceae & $\mathrm{E}$ & 2 \\
\hline Ceiba speciosa (A.St.-Hil.) Ravenna & paineira & Malvaceae & $\mathrm{NBH}$ & 2 \\
\hline Pleroma granulosum (Desr.) D. Don & quaresmeira & Melastomataceae & $\mathrm{N}$ & 2 \\
\hline Leucaena leucocephala (Lam.) de Wit & leucena & Fabaceae & $\mathrm{E}$ & 2 \\
\hline Schinus terebinthifolia Raddi & aroeira & Anacardiaceae & $\mathrm{NBH}$ & 1 \\
\hline Schinus molle L. & aroeira-salsa & Anacardiaceae & $\mathrm{N}$ & 1 \\
\hline Ficus benjamina $\mathrm{L}$. & ficus & Moraceae & $\mathrm{E}$ & 1 \\
\hline Ficus elastica Roxb. ex Hornem. & árvore-da-borracha & Moraceae & $\mathrm{E}$ & 1 \\
\hline Ficus microcarpa L. f. & figueira & Moraceae & $\mathrm{E}$ & 1 \\
\hline Handroanthus chrysotrichus. (Mart. ex DC.) Mattos & ipê-tabaco & Bignoniaceae & $\mathrm{NBH}$ & 1 \\
\hline Artocarpus heterophyllus Lam. & jaqueira & Moraceae & $\mathrm{E}$ & 1 \\
\hline Ligustrum lucidum W.T.Aiton & alfeneiro & Oleaceae & $\mathrm{E}$ & 1 \\
\hline Licania kunthiana Hook.f. & marinheiro & Chrysobalanaceae & $\mathrm{NBH}$ & 1 \\
\hline Salix viminalis $\mathrm{L}$. & salgueiro & Salicaceae & $\mathrm{E}$ & 1 \\
\hline \multirow[t]{2}{*}{ Handroanthus sp. } & ipê & Bignoniaceae & & 1 \\
\hline & não identificada & & & 2 \\
\hline
\end{tabular}

Observou-se que apenas sete espécies foram responsáveis por aproximadamente $60 \%$ das quedas registradas, destas, destacam-se as espécies Pachira aquatica e Libidibia ferrea var. leiostachya responsáveis por $10,1 \%$ das ocorrências cada uma e Poincianella pluviosa (8,7\%). Mendes et al. (2016), em Piracicaba - SP, também verificaram que os indivíduos da espécie Pachira aquatica foram os mais vulneráveis a queda, seguidos pelos indivíduos de Handroanthus sp. (ipê roxo) e Tipuana tipu.

Em Belo Horizonte, Pachira aquatica foi a espécie com maior frequência de queda, ocasionada prioritariamente pelo ataque de Euchroma gigantea (besouro metálico), que pôde ser visualizado devido ao "descolamento" da raiz e tronco. As demais espécies não apresentaram um motivo que prevalecesse. Registros de ataques severos do besouro metálico em Pachira aquatica nas cidades de São Paulo, Goiânia e Distrito Federal acarretaram na necessidade de remoção de várias árvores (Fonseca 2010).

Constatou-se um número significativo de quedas caracterizada por indivíduos de espécies nativas do Brasil $(57,6 \%)$ contra $42,4 \%$ de indivíduos de espécies exóticas. Porém, quando se fala em espécies nativas o importante é considerar a região do estudo, principalmente diante de uma país megadiverso e extenso, como o Brasil. Assim, considerando-se as espécies nativas da região de Belo Horizonte, tem-se a diminuição dessa proporção, caindo para 36,4\% dos casos, a diferença de $21,2 \%$ são aquelas espécies utilizadas na cidade, nativas do Brasil, mas não da região.

Selecionar uma espécie pelo fato de ser nativa não é o suficiente para o sucesso de sua adaptação no meio urbano e não garante a permanência dos mesmos padrões verificados no ambiente natural (Biondi 2011). A mesma autora afirma que antes de indicar qualquer espécie nova é necessário realizar 
uma série experimentos e monitoramento, pois muitas vezes a espécie assume um comportamento que foge dos padrões esperados. As plantas podem atingir maiores ou menores valores de altura, DAP e diâmetro de copa do que comumente apresentam nas florestas, bem como, diferentes períodos e intensidade de floração, frutificação e foliação. Além disso, podem distinguir sua característica de enraizamento e desenvolvimento de copa.

A maioria das árvores que caíram eram indivíduos de grande porte $(76,8 \%)$, apenas quatro ocorrências foram com árvores de pequeno porte. Com relação a DAP, foi possível notar uma frequência maior na classe de diâmetro entre 30 e 49 $\mathrm{cm}(41,2 \%)$, seguida pela classe entre 50 e $69 \mathrm{~cm}$ $(23,5 \%)$. A caracterização do DAP para cada porte pode ser observada na Figura 2

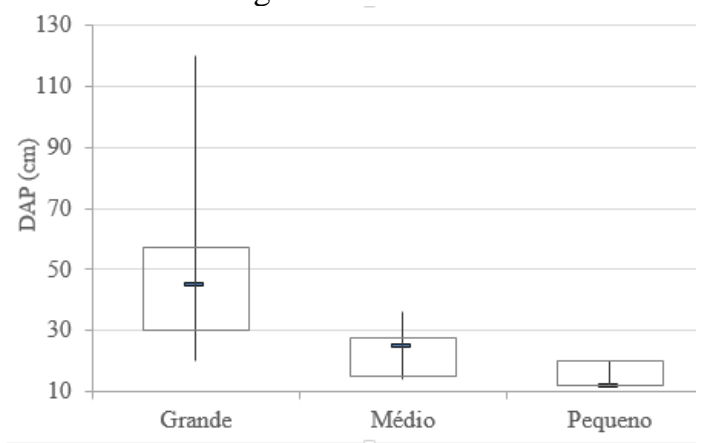

Figura 2. Gráfico Box plot elaborado para relacionar as classes de tamanho com as dimensões de DAP.

Observa-se a distribuição regular de DAP por classe de tamanho, árvores de grande porte caracterizaram-se por maiores dimensões de diâmetro e árvores menores pelo inverso. A média do DAP para as árvores de grande porte foi de 50,9 $\mathrm{cm}$, para as de médio porte $22,9 \mathrm{~cm}$ e pequeno porte $14,7 \mathrm{~cm}$.

A ocorrência da queda de árvores com maior porte é um indicativo para analisar a compatibilidade entre seu tamanho e o espaço disponível para seu crescimento, uma vez que este pode ser insuficiente, indicando que a relação projeção de copa e tamanho de raiz não ocorre nessas condições. Ao analisar as condições de plantio dos indivíduos que caíram, pode-se comprovar essa afirmação (Figura 3).

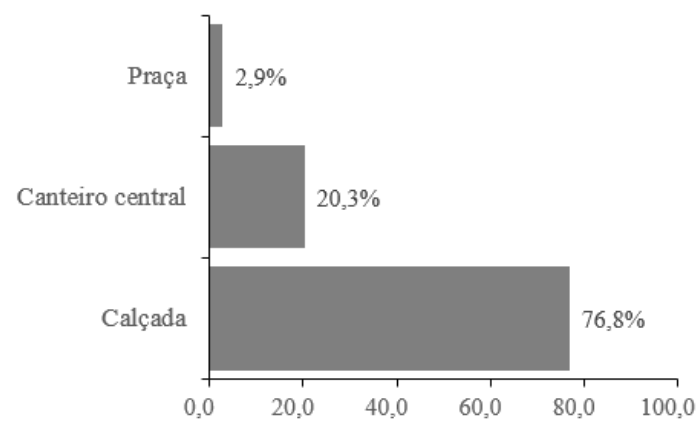

Figura 3. Proporção de queda de árvores por local de plantio.
Observa-se que grande parte dos indivíduos que sofreram queda, estavam plantados nas calçadas, local com a menor área de crescimento disponível para as plantas. Ambiente mais restritivo do que comparado com uma praça ou parque por exemplo. Os únicos dois casos de queda em praça ocorreram devido ao ataque de Euchroma gigantea (Linnaeus, 1758) (besouro metálico) em munguba e a um plantio feito de forma desnivelada de sibipiruna, esta possivelmente teve seu equilíbrio alterado após a remoção de uma estrutura que servia como mureta para limitar seu crescimento.

Essa atenção para o espaço de crescimento das raízes já foi destacada por Pereira (2017). A autora verificou que o tamanho inadequado dos canteiros interfere no desenvolvimento dos indivíduos, favorecendo o estrangulamento das raízes e o afloramento nas calçadas. Além disso, a qualidade do sistema radicular é influenciada pelas condições do ambiente onde se encontram inseridos, interferindo na estabilidade das árvores, que depende enormemente da arquitetura e da ancoragem do sistema radicular no solo.

Os problemas fitossanitários foram observados em apenas 20,3\% das árvores que caíram e embora existentes, na maioria dos casos não eram expressivos a ponto de justificarem uma remoção. Conceição et al. (2017), ao propor um sistema de avaliação do risco potencial de queda de árvores, enfatizou que devido aos possíveis danos que uma queda de árvore pode causar é relevante conhecer as condições fitossanitárias das árvores em locais públicos com grande fluxo de pessoas. Contudo, o resultado encontrado nesta pesquisa contradiz tal informação, o que sugere mudanças de direção para a elaboração de novos métodos de análise de risco, uma vez que a maioria prioriza a abordagem fitossanitária. Uma análise das condições de plantio, da compatibilidade física entre a espécie e o espaço disponível, bem como a dinâmica do balanço de forças atuantes, mostram-se necessárias.

Ainda, neste contexto, Moore (2014) afirma que as práticas de manejo têm uma profunda influência na saúde de árvores envelhecidas que crescem sob estresse ambiental. As árvores quando em locais ideais, onde não estão sujeitas a práticas de manejo invasivo (como remoção de copa em elevadas proporções, podas de galhos com diâmetro acentuado e de raízes estruturais), que afetam seu sistema radicular ou copa, permanecem saudáveis e vigorosas à medida que envelhecem e são capazes de lidar com muitas pragas, doenças e estresses que poderiam afetá-las.

$\mathrm{O}$ besouro metálico e o ataque de cupins nas raízes foram os problemas mais frequentes encontrados nesta pesquisa, a podridão e presença de fungo foram observados em uma única árvore, cada. Os sinais da presença do besouro metálico na planta ocorrem à medida que constroem as galerias, pois as larvas liberam serragem misturada com fezes, o que 
forma uma massa marrom na região do colo, deixando evidente o ataque (Fonseca 2010). Com relação aos cupins, Zorxenon (2007) afirma que devido a urbanização crescente e a ocupação desordenada dos espaços naturais nas áreas antes dominadas pelos cupins nativos, bem como pela introdução e dispersão de espécies exóticas, houve o agravamento das infestações tanto em árvores, quanto em edificações e jardins, pois os cupins passaram a infestar tais elementos em substituição ao alimento outrora encontrado naturalmente. $\mathrm{O}$ autor chama atenção ainda para a correlação significativa entre o nível de danos internos provocados pelos cupins e o CAP das árvores, que ocorre provavelmente, devido a existência de substancias químicas com efeito inibidor em árvores mais jovens.

Outro resultado que também merece destaque é a informação sobre o local de ruptura da árvore (Figura 4). Na maioria dos casos ocorreu a queda devido a ruptura das raízes $(82,6 \%)$, sendo proporções menos expressivas para a porção do colo e tronco. Quando a ruptura ocorreu no tronco, isso se deu, em média, a 1,54 $\mathrm{m}$ de altura.

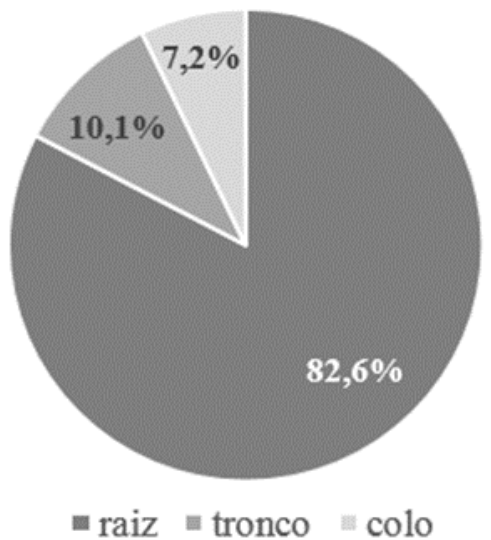

Figura 4. Proporções das ocorrências por área de ruptura.
Na cidade de Pasadena (Califórnia, EUA), uma análise sobre o local de ruptura das árvores demonstrou que $56,2 \%$ apresentaram ruptura de galhos, $30,8 \%$ ruptura de raiz, $7,2 \%$ ruptura do tronco e 5,8\% outros tipos de danos (Davey Resourse Group 2012). Embora, não tenha sito o resultado mais frequente, a ruptura de raiz, também foi expressivo no estudo em questão.

No caso de ruptura das raízes os fatores costumam ser provocados pela falta de enraizamento adequado, pois ocorre o desenvolvimento insuficiente deste órgão devido à forma e ao local de plantio, em especial, compactação do solo, ou devido à redução de sua resistência em função de deteriorações (Cavalcanti 2018).

A qualidade do colo, tronco e copa, avaliados após a queda das árvores revela um agravante frente às tradicionais metodologias para gestão de risco das árvores (Figura 5). Isto porque todas as partes das árvores apresentaram predominantemente condições boas de qualidade. Não sendo possível observar visualmente qualquer problema.

Estes resultados evidenciaram que o principal fator que contribuiu para a queda das árvores não é comumente analisado nas metodologias aplicadas para a gestão de risco, acentuando ainda mais a necessidade de se investigar a condição das raízes destes indivíduos.

A queda de árvores em Belo Horizonte, tem sido frequente após a ocorrência de eventos meteorológicos extremos, como tempestades ou vendaval. Por esse motivo, foi desenvolvida também uma análise sobre as condições meteorológicas dos dias em que as árvores amostradas caíram (Figura 6).
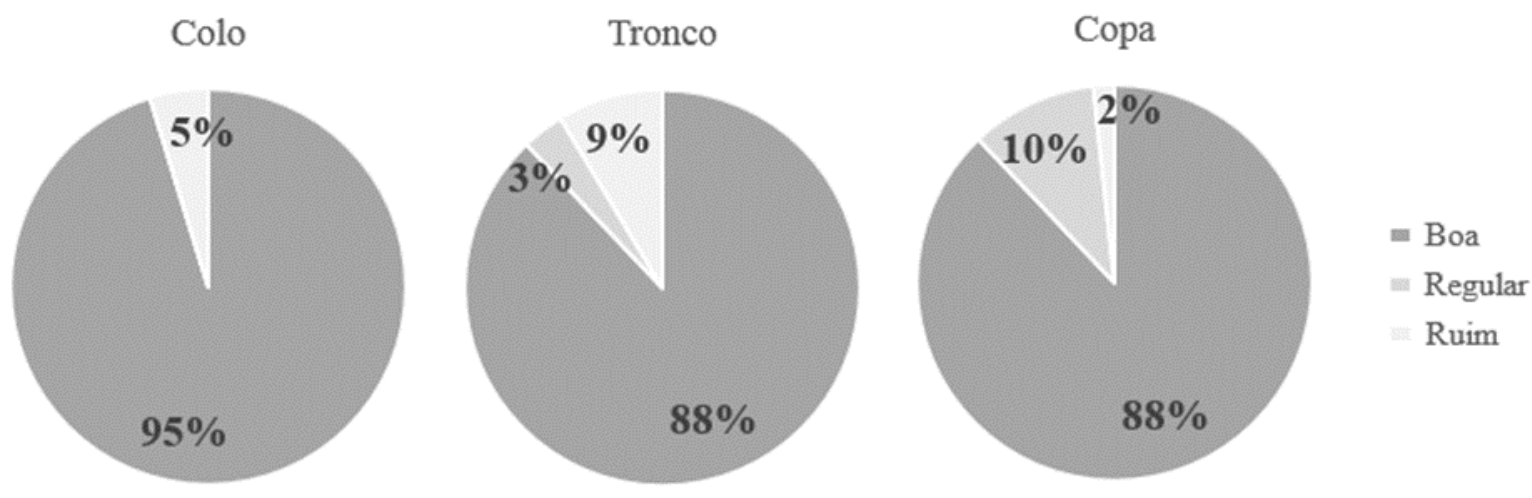

Figura 5. Proporção encontrada para os aspectos de qualidade das árvores 


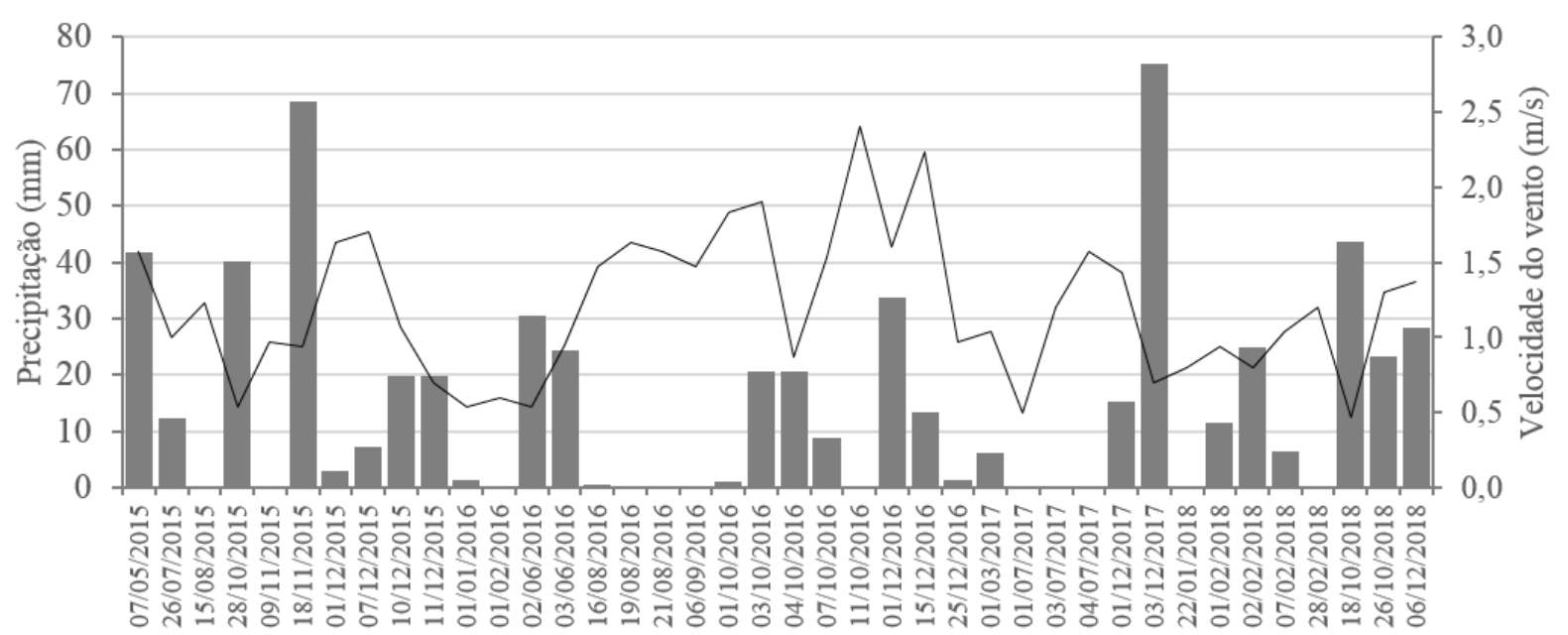

Figura 6. Registro dos dados meteorológicos do INMET para as variáveis velocidade do vento (linha) e precipitação (coluna).

A velocidade do vento média nos dias de queda foi de aproximadamente $1,12 \mathrm{~m} / \mathrm{s}$, sendo o registro máximo de $2,40 \mathrm{~m} / \mathrm{s}$. A maioria dos registros de queda ocorreram em dias que apresentaram ventos fortes $(78,6 \%)$, tendo apenas um caso em dia de vento fraco. A queda de árvores, na base, provocada por ventos, denomina-se arrancamento, isto ocorre quando a força exercida pelos ventos, ao incidir horizontalmente sobre a parte exposta da árvore, gera uma combinação de torques por torção e flexão na base desta, assim, se esse torque for maior que a resistência do sistema de enraizamento da árvore, ocorre a queda (Ataíde et al. 2015).

Com relação as chuvas, nos dias em que a chuva contribuiu para a queda de árvores a precipitação média registrada foi de $23,12 \mathrm{~mm}$, ocorrendo dias com 75,3 mm e 68,6 mm. Observouse que a metade das ocorrências foram imediatamente após uma forte precipitação, outros $37,1 \%$ dos casos ocorreram após eventos de precipitação constante. A queda de árvores sem a incidência de precipitação e ventos fortes representou $12,9 \%$ da amostragem, composta principalmente por ataque de Euchroma gigantea em munguba (metade dos casos), ataque de cupins no sistema radicular e desequilíbrio da copa atrelado a inclinação do tronco.

De todas as árvores amostradas, apenas $16,1 \%$ não provocaram algum tipo de dano ao cair. Todo o restante gerou algum tipo de inconveniente (Figura 7).

A principal consequência gerada pela queda de árvores em Belo Horizonte foi a interferência no trânsito de veículos, 43,8\% das ocorrências prejudicaram este componente. Em seguida tem-se em destaque os danos aos veículos e rede elétrica. Em aproximadamente $4 \%$ dos casos de queda, as árvores chegaram a atingir pessoas. Na categoria outros, foram enquadrados problemas pontuais, como: atingir residência, quebra de marquise, interrupção de tráfego de trens e dano ao patrimônio (cúpula de vidro do Museu Abílio Barreto).

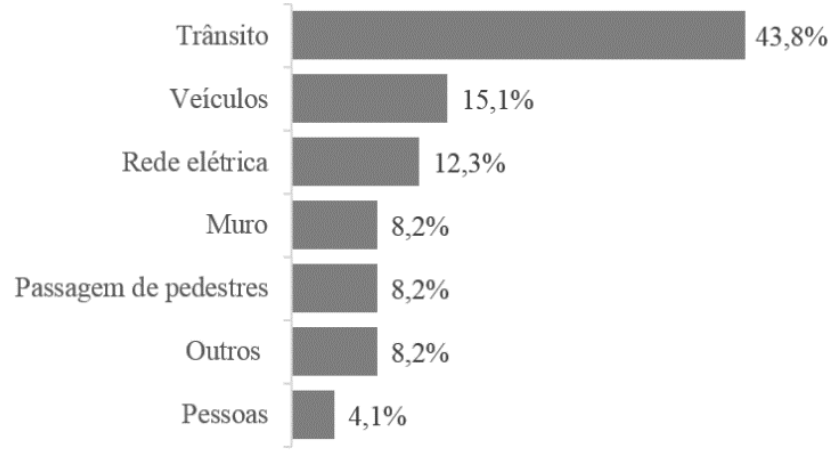

Figura 7. Problemas gerados pela queda de e árvores em Belo Horizonte.

\section{Conclusão}

O diagnóstico sobre a queda de árvores urbanas em Belo Horizonte, mostrou-se como uma atividade fundamental para direcionar e corrigir as ações de planejamento e gestão da arborização. Os resultados indicaram que a condição fitossanitária da árvore não é o ponto que merece maior atenção em uma análise de risco, pois foram poucos os casos verificados com tais problemas. A maioria das árvores que caíram apresentavam boas condições quanto a qualidade do colo, tronco e copa.

As espécies com maior número de queda foram Pachira aquatica (munguba), Libidibia ferrea var. leiostachya (pau-ferro) e Poincianella pluviosa (sibipiruna). Destas, apenas a munguba apresentou problemas fitossanitários, caracterizado pelo ataque do besouro metálico. Destaca-se ainda que mais da metade das ocorrências amostradas nesta pesquisa foram com indivíduos de espécies nativas do Brasil.

$\mathrm{O}$ local de ruptura nas árvores foi predominantemente nas raízes. Esta informação também contribui para repensar as metodologias de 
avaliação e os critérios adotados no planejamento, pois tudo indica a crer que a falta de espaço ou a dificuldade de penetração no substrato pelas raízes é o responsável principal para a queda das árvores de grande porte, uma vez que estas não conseguem condições de ancoragem suficiente para se manter em pé ao longo do tempo.

Por fim, comprovou-se que as condições meteorológicas, abordadas nas análises de risco, consideradas componentes ambientais facilitadores para a queda, realmente desempenham esse papel. A maioria das ocorrências foram em dias de acentuada precipitação e velocidade do vento. Como principal problema gerado com a queda de árvores para a cidade tem a interferência no trânsito, prejuízos com a rede elétrica e quebra de muros também foram frequentes.

Os resultados demonstraram indícios de que a condição de plantio aliado ao porte das árvores foram os principais componentes facilitadores para a queda, uma vez que a maioria das árvores que caíram eram de grande porte e estavam plantadas nas calçadas, com pouca ou nenhuma área de crescimento. Desta forma, o risco que uma árvore proporciona para a cidade, está diretamente relacionado aos critérios de seleção e escolha do local de plantio, sendo um indício da falta de planejamento correto, ao invés de falta de saúde das árvores.

\section{Referencias}

Assis WL (2010) O sistema clima urbano do município de Belo Horizonte na perspectiva têmporo-espacial. Dissertação, Instituto de Geociências, Universidade Federal de Minas Gerais. $299 \mathrm{f}$.

Ataíde GM, Castro RVO, Correia ACG, Reis GG, Reis MGF, Rosado AM (2015) Interação árvores e ventos: aspectos ecofisiológicos e silviculturais, Ciência Florestal, $25 \quad$ (2): 523-536. doi:10.5902/1980509818472

Biondi D (2011) Introdução de espécies na arborização de ruas. In: Biondi D. (ed) Pesquisa em arborização de ruas. Curitiba: O Autor. p. 09-28.

Bressane A, Bagatini JA, Biagolini $\mathrm{CH}$, Roveda JAF, Roveda SRMM, Fengler FH, Longo RM (2018) Neuro-Fuzzy Modeling: A Promising Alternative For Risk Analysis In Urban Afforestation Management. Revista Árvore,42(1): 110.doi:10.1590/1806-90882018000100006

Cavalcanti NMO (2018) Propriedade da madeira de raízes de árvores urbanas. Dissertação, Faculdade de Engenharia Agrícola, Universidade Estadual de Campinas. 59p.
Conceição IJ, Samolão RP, Santana AC (2017). Proposal for a system of trees fall potential risk assessment in urban parks. Revista Árvore, 41 (4): e410408. doi:10.1590/1806-90882017000400008

Davey Resourse Group (2012). Pasadena Windstorm Tree Failure Analysis. Ohio: Davey Resourse Group.

Fonseca APP (2010) Aspectos biológicos de Euchroma gigantea (Linnaeus, 1758) (Coleoptera: Buprestidae) em Pachira aquatica Aubl. (1775) (Bombacaceae). Dissertação, Universidade Federal de Alagoas. 82p.

Instituto Brasileiro de Geografia e Estatística (IBGE). Cidades: Belo Horizonte. Disponível em: < https://cidades.ibge.gov.br/>. Acesso em: 17 mar. 2019.

Martins FB, Gonzaga G, Santos DF, Reboita MS (2018) Classificação climática de Köppen e de Thornthwaite para Minas Gerais: cenário atual e projeções futuras. Revista Brasileira de Climatologia, 14 (Edição Especial Dossiê Climatologia de Minas Gerais): 129-156. doi: 10.5380/abclima.v1i0.60896

Mendes FH, Polizel JL, Silva Filho DFda (2016) O efeito do vento nas quedas de árvores em Piracicaba/SP. Ciência e Natura, 38 (3): 1523-1535. doi: $10.5902 / 2179460 \mathrm{X} 21355$

Moore GM (2014) Wind-Thrown Trees: Storms or Management? Arboriculture \& Urban Forestry, 40 (2): 53-69.

Moser P, Da Silva AC, Higuchi P, Dos Santos EM, Schmitz V (2010) Avaliação pós-tempestade da Arborização do Campus da Universidade do Estado de Santa Catarina, Lages-SC. Revista da Sociedade Brasileira de Arborização Urbana, 5 (2): 40-51.

Pena JCC, Magalhães DM, Moura ACM, Young RJ, Rodrigues M (2016) The Green Infrastructure of a Highly-Urbanized Neotropical City: The Role of The Urban Vegetation In Preserving Native Biodiversity. Revista da Sociedade Brasileira de Arborização Urbana, 11 (4): 66-78. doi: 10.5380/revsbau.v11i4.63481

Pereira B (2017) Análise dos efeitos do entorno urbano sobre o sistema radicular de árvores viárias de São Mateus do Sul- Paraná. Trabalho de Conclusão de Curso, Universidade Tecnológica Federal do Paraná. 103 p.

Pereira PH, Topanotti LR, Dallacort S, Mota CJDA, Brun FGK, Silva RTL (2011) Estudo de Caso do Risco de Queda de Árvores Urbanas em Via Pública 
na Cidade de Dois Vizinhos-PR. Synergismus scyentifica, 06 (1): não paginada.

Sampaio ACF, Duarte FG, Silva EGC, De Angelis BLD, Blun CT (2010) Avaliação de árvores de risco na arborização de vias públicas de Nova Olímpia, Paraná, Revista da Sociedade Brasileira de Arborização Urbana, 5 (2) :82-104.

Skärbäck E (2007) Urban forests as compensation measures for infrastructure development. Urban Forestry \& Urban Greening, 6 (4): 279-285. doi: 10.1016/j.ufug.2007.05.006

Volpe-Filik A, Silva LF, Lima AMLP (2007) Avaliação da arborização de ruas do bairro São Dimas na cidade de Piracicaba/SP através de parâmetros qualitativos. Revista da Sociedade Brasileira de Arborização Urbana, 2 (1): 34-43.

Zorzenon FJ (2007) Levantamento, dimensionamento de danos e manejo de cupins subterrâneos e formigas carpinteiras em arborização urbana. Dissertação, Instituto Biológico, Agência Paulista de Tecnologia dos Agronegócios. 133 p. 